\title{
A Barrier to Exclusive Breastfeeding for WIC Enrollees: Limited Use of Exclusive Breastfeeding Food Package for Mothers
}

\author{
Alison Volpe Holmes, ${ }^{1,2}$ Nancy P. Chin, ${ }^{3}$ Jeffery Kaczorowski, ${ }^{4}$ and Cindy R. Howard ${ }^{4,5}$
}

\begin{abstract}
Background: In the first 2 weeks of life, most breastfeeding mother-infant dyads in the Special Supplemental Nutrition Program for Women, Infants, and Children (WIC) receive infant formula from WIC, instead of a larger food package designed for exclusively breastfeeding mothers. This study was designed to explore reasons for high rates of formula supplementation of breastfeeding newborns enrolled in WIC and the limited use of the WIC expanded food package.

Methods: We conducted in-depth interviews with 29 mothers who either partially or exclusively breastfed for at least 2 months. Interviews were transcribed verbatim, analyzed, coded, and organized into 10 themes.

Results: Participants view the WIC program in a contradictory manner. They see it as highly supportive of breastfeeding, but also as a promoter of infant formula. The expanded food package for mothers is not valued, but free supplemental formula is highly valued. Misinformation about breastfeeding pervades the healthcare system, and exclusive breastfeeding is not promoted as an important health goal. Lack of access to breast pumps, the unacceptability of pumping in the workplace, and difficulties with nursing in public all contribute to formula supplementation.

Conclusions: The healthcare system, the WIC program, and demands of daily life all contribute to low rates of exclusive breastfeeding in the WIC program. The available expanded food package for mothers who are exclusively breastfeeding is both disliked and underutilized, while free supplemental formula is rarely discouraged.
\end{abstract}

\section{Introduction}

$\mathbf{S}_{\mathrm{b}}^{\mathrm{N}}$ IX MONTHS OF EXCLUSIVE BREASTFEEDING are recommended by all major health organizations. ${ }^{1-4}$ Traditionally underserved populations, including those enrolled in the Special Supplemental Nutrition Program for Women, Infants, and Children (WIC), have both lower rates of exclusive breastfeeding and more health morbidities. ${ }^{5-8}$ These higherrisk mothers and children can particularly benefit from the health advantages of 6 months of exclusive breastfeeding. ${ }^{9-14}$ In the U.S. in 2004, at hospital discharge, 52\% of non-WIC infants were exclusively breastfed versus $30 \%$ of WIC-enrolled infants. At 6 months the discrepancy holds with exclusive breastfeeding for $24 \%$ of non-WIC infants but only
$11 \%$ of WIC-enrolled infants. ${ }^{5}$ Mothers who exclusively breastfeed receive additional foods in their WIC mother's package but do not receive infant formula. Once the decision to add infant formula is made, the mother forfeits her expanded food package ${ }^{15}$ (Monroe County, New York, WIC program, personal communication). In New York State in $2005,85 \%$ of WIC-enrolled mothers who breastfed in the hospital received infant formula instead of the expanded food package at a first postpartum WIC visit (New York State Department of Health, personal communication). This visit generally occurs in the first 10 days of life, before breastfeeding is well established.

Factors associated with breastfeeding success in the WIC program include some prenatal breastfeeding education pro-

${ }^{1}$ Department of Pediatrics, Concord Hospital, Concord; and ${ }^{2}$ Department of Community and Family Medicine, Dartmouth Medical School, Hanover, New Hampshire.

Departments of ${ }^{3}$ Community and Preventive Medicine and ${ }^{4}$ Pediatrics, University of Rochester; and ${ }^{5}$ Department of Pediatrics, Rochester General Hospital, Rochester, New York.

This research was presented in part at the 2006 Annual Conference of the Academy of Breastfeeding Medicine, Niagara Falls, New York, and at the 2007 meeting of the Pediatric Academic Societies, Toronto, Ontario, Canada. 
grams, breastfeeding peer counseling, and professional support from lactation specialists in the WIC program. ${ }^{16-21}$ Reasons breastfeeding mothers in WIC cite for stopping breastfeeding include lack of confidence in their ability to breastfeed, beliefs that their infants prefer or need formula, and personal circumstances that are incompatible with breastfeeding. ${ }^{22-25}$ Prior to this study no one had ever investigated why few breastfeeding mothers obtain the WIC expanded food package instead of formula, or why formula is obtained even when breastfeeding is going well. In embarking on the current study, the authors and community WIC partners thought that possible reasons for poor expanded food package rates include not knowing about the package, finding its contents unappealing, or the assumption on the part of either mothers or WIC staff that WIC-enrolled infants should receive formula. Since additional reasons not readily apparent to the investigators were also possible, we used qualitative interviews to determine why the expanded food package is rarely utilized. Qualitative methods are appropriate when there is little or no prior information on a topic or it is poorly understood. ${ }^{26}$

\section{Subjects and Methods}

\section{Setting and preparation}

We worked with three WIC sites in Monroe County, New York, representing inner city urban, urban/suburban, and rural locations. In 2005, Monroe County had 732,057 residents, including 209,662 urban residents in the city of Rochester. ${ }^{27}$ The three sites serve $>90 \%$ of all WIC participants in the county. The first author (A.V.H.) informally interviewed WIC clients in waiting rooms and WIC nutritionists during breaks in their day, and three authors (A.V.H., N.P.C., and C.R.H.) analyzed WIC printed materials about breastfeeding. From this initial informal assessment and document analysis, we generated open-ended questions about exclusive breastfeeding and WIC food packages. To begin a qualitative study, one must focus the interview questions around a "logic model," a way of describing structure and changes among things or events. Our logic model focused on the central contradiction of WIC as both a breastfeeding support program and a provider of free formula to breastfeeding mothers.

We conducted two pilot interviews with WIC-enrolled breastfeeding mothers, to be certain our questions led to indepth discussions about breastfeeding and food package decisions. The data gathered in the pilot interviews were not included in the formal analysis. The mixed methods in the preparation phase of the study triangulated information sources to generate robust questions for the formal interviewing phase.

\section{Data collection}

We recruited mothers enrolled in the WIC program who had breastfed a child, either exclusively or partially, for at least 2 months within the prior 18 months. WIC nutritionists and lactation consultants identified eligible clients. The first author (A.V.H.) contacted potential participants by telephone, verified eligibility, and arranged interviews. We obtained approval from the Institutional Review Boards of the University of Rochester School of Medicine and Dentistry, the Anthony Jordan Community Health Center, the Oak Orchard Community Health Center, the Monroe County Department of Health, and the New York State Department of Health. At the interview, an information sheet describing the study was given to participants.

Purposive sampling was used in recruitment. Purposive sampling is a qualitative method that allows for some degree of guaranteeing diversity in the study population regarding characteristics known to be associated with the outcome of interest-exclusive breastfeeding. When screening for eligibility, we ascertained that at least two of our 29 participants fulfilled a demographic characteristic in each category: (1) prior breastfeeding experience-successful, unsuccessful, or first experience; (2) residence-inner city urban, suburban, or rural; (3) primiparous or multiparous; (4) education-less than high school, high school graduate, some college, or university degree or higher; (5) race-AfricanAmerican, white, or Latina; (6) work and/or school-full time, part time, or none; (7) age $-<20$ years, 20-29 years, or $>29$ years; (8) U.S. or foreign born; (9) family structuremarried, cohabitating, extended family, or mother and children alone; and (10) WIC food package at first postpartum visit-infant formula or expanded food package (Table 1).

The first author (A.V.H.) conducted interviews in November and December 2005 at either the participant's home or at a coffee shop. Mothers began by describing breastfeeding of the index child and other children. We then asked if, why, and how the breastfeeding mother added infant formula or expressed breastmilk in bottles to her infant's diet. Mothers were allowed to elaborate on all factors that affected infant feeding decisions. We also asked about interactions with WIC, doctors, other health professionals, relatives, friends, and acquaintances that did or did not lead to the first introduction of formula or to its continued use. Finally, we explored why or why not exclusively breastfeeding mothers often received formula from WIC, instead of the expanded food package. When participants brought up issues we had not anticipated (i.e., mastitis due to inability to express milk at work), we asked about these participant-driven concerns in future interviews. Interviews typically lasted 45 to 60 minutes. After completing the interview, the participant was given a $\$ 50$ gift card as compensation.

\section{Data analysis}

Interviews were digitally recorded, transcribed verbatim, and reviewed for quality control. All four authors (three general pediatricians and one anthropologist/qualitative health researcher) reviewed the transcripts and coded for themes. No new themes emerged after 22 interviews, a condition known as "saturation of themes" or "redundancy." No further interviews are necessary after redundancy, since no new information will likely be obtained. The authors decided to finish all other scheduled interviews in order to maintain community trust, bringing the total to 29 . No new themes emerged in the last seven interviews, but quotes from these interviews supporting the previously generated themes were included in the analysis.

The transcripts were kept as Microsoft (Redmond, WA) Word documents, and quotes from the interviews were placed into 20 theme documents. During this "cutting and sorting" phase, 10 of the themes were collapsed down into 
Table 1. Demographics of Study Population as Used in Purposive Sampling Scheme

\begin{tabular}{|c|c|}
\hline Demographic & Number of participants \\
\hline \multicolumn{2}{|l|}{ Prior breastfeeding experience } \\
\hline Successful & 12 \\
\hline Unsuccessful & 4 \\
\hline Both successful and unsuccessful & 4 \\
\hline First time & 9 \\
\hline \multicolumn{2}{|l|}{ Residence } \\
\hline Urban & 13 \\
\hline Suburban & 8 \\
\hline Rural & 8 \\
\hline \multicolumn{2}{|l|}{ Parity } \\
\hline Multiparous & 20 \\
\hline Primiparous & 9 \\
\hline \multicolumn{2}{|l|}{ Education } \\
\hline Less than high school & 3 \\
\hline High school graduate & 11 \\
\hline Some college & 11 \\
\hline College graduate & 4 \\
\hline \multicolumn{2}{|l|}{ Race } \\
\hline African-American & 12 \\
\hline White & 13 \\
\hline Hispanic & 4 \\
\hline \multicolumn{2}{|l|}{ Work and/or school } \\
\hline Full time (40 hours/week) & 8 \\
\hline Part time & 6 \\
\hline None & 15 \\
\hline \multicolumn{2}{|l|}{ Age } \\
\hline 20 years & 4 \\
\hline 20-29 years & 18 \\
\hline 29 years & 7 \\
\hline \multicolumn{2}{|l|}{ U.S. born } \\
\hline Yes & 27 \\
\hline No & 2 \\
\hline \multicolumn{2}{|l|}{ Family structure } \\
\hline Married & 14 \\
\hline Cohabitating with father & 2 \\
\hline Living with other family & 6 \\
\hline Mother and child(ren) alone & 7 \\
\hline \multicolumn{2}{|l|}{ Food package at first WIC visit } \\
\hline Formula & 13 \\
\hline Expanded exclusive breastfeeding & 16 \\
\hline \multicolumn{2}{|l|}{ Reason for food package } \\
\hline Never received formula & 9 \\
\hline Expanded first, formula later & 7 \\
\hline Used formula from start & 4 \\
\hline $\begin{array}{l}\text { Got formula from start even though } \\
\text { exclusively breastfeeding }\end{array}$ & 7 \\
\hline $\begin{array}{l}\text { Formula at first visit, changed to } \\
\text { expanded later }\end{array}$ & 2 \\
\hline \multicolumn{2}{|l|}{ Reasons for formula use } \\
\hline Work & 10 \\
\hline Perceived insufficient milk & 3 \\
\hline Being out in public & 5 \\
\hline
\end{tabular}

the others for a final total of 10 themes. For example, "Work causes formula supplementation," "School causes formula supplementation," and "Bosses and co-workers are unsupportive of breastfeeding needs at work" were all combined into Theme 9, "Work and school are key reasons for formula supplementation." All interview quotes were cut and sorted, but only a non-redundant, illustrative subset is shown in Table 2.

\section{Results}

The 29 interviews generated 10 themes about difficulties with exclusive breastfeeding and poor utilization of the expanded food package. Table 2 lists the themes and cites quotes for each.

The WIC program was viewed as supportive of breastfeeding, but was also seen as supporting supplementation of breastfed infants with formula, including offers of formula to breastfeeding mothers who did not want it. Mothers were either unaware of the expanded food package or uninterested in it because it was unappealing or contained foods that were difficult or time-consuming to prepare. Conversely, infant formula was highly valued, even by breastfeeding mothers, because it was perceived as an expensive item (Table 2, themes 1 and 2).

Formula supplementation was often used after birth in the hospital. Mothers believed that since supplementation occurred in a healthcare setting, that they should continue it at home. After leaving the hospital, mothers were told by doctors to stop breastfeeding or to supplement with formula for many reasons, as healthcare providers did not appear to consider benefits of lactation in medical decision-making. No one cited a health professional who counseled her to stop formula supplementation (Table 2, theme 3).

Mothers perceive that the health benefits of breastfeeding are transmitted with any level of breastfeeding; a baby whose diet includes both breastmilk and formula is viewed as receiving the same benefits as those who are exclusively breastfed. This provides little incentive to turn down free formula from WIC. Mothers in WIC did not know that nursing more often increases milk supply or that, conversely, supplementing with formula decreases milk supply, nor did WIC or healthcare providers educate them about this. Skipping a nursing session and using formula caused physical pain and mastitis. Anxiety about milk production was common. Reassurance about weight gain or urine output was not mentioned. Formula was seen as a "back up plan" for nursing not going well, not as something that might harm breastfeeding (Table 2, themes 4-6).

Work was a main reason for introducing formula, due to the unpredictability of work hours, wanting to get the baby "used to" formula, and multiple workplace barriers to milk expression and storage. Mothers told stories about pumping "extra" in their off-time at home, but going through the work or school day without pumping or expressing. Breastfeeding a baby was viewed as easier than formula feeding when the mother was present, but the logistics of expressing human milk for later feeding was deemed too complicated. Mothers described problems with pumps, including difficulty finding one that was comfortable or affordable. Mothers brought bottles with them on outings, because breastfeeding outside the home was viewed as inappropriate, embarrassing, or upsetting to a male partner. Strangers made open comments about women who breastfed in public (Table 2, themes 7-10).

\section{Discussion}

This study illustrates previously undescribed barriers to exclusive breastfeeding for WIC participants. Our consensus explanations are: First, that exclusively breastfeeding mothers did not know about, accept, or value the food package 
Table 2. Themes and Supporting Quotes About Barriers to Exclusive Breastfeeding For WIC Enrollees and Barriers to Utilization of Expanded Food Package

Theme

Selected quotes

1. WIC promotes breastfeeding, but also promotes supplementation with infant formula.

2. A mother's exclusive breastfeeding food package is not valued, but free formula is highly valued.

3. Hospitals and doctors promote formula; subsequent exclusive breastfeeding is not encouraged.

4. Benefits of exclusive breastfeeding are not understood, even by those who practice it, so one should accept free formula.

5. The supply-and-demand nature of human milk production is rarely understood until after formula supplementation has caused supply to decrease.

6. Formula is viewed as a crucial reserve-not as something that may harm breastfeeding.

7. Work and school are key reasons for formula supplementation.

8. Few breastfeeding mothers pump or express milk at work or school, leading to pain, illness, and formula supplementation.

9. Pumping milk for later feeding can be challenging-formula is easier in a mother's absence.

10. Nursing in public is not accepted.
"They said, 'At any point you could run into problems.' They said, 'there's no chance of you using formula?' I didn't really want the formula. I kept asking them, 'Can't I go lower, can't I get rid of it'. They said, 'What if, what if . . .' "'

"I would rather let my package down to get the formula for her, because the Enfamil with iron is 20 something dollars a can. I can go buy myself a couple of cans of tuna."

"Then they asked me if I wanted tuna and beans. I just told them to keep it, I don't want any of that stuff, I don't eat any of it."

"I always did both just because that was the way I did it in the hospital."

"The doctor said, 'No breastfeeding until we know what's wrong!' "“

"I think they get all the benefits even with formula. I don't see why they wouldn't because they're still getting breastfed."

"I wanted to do both, but I realized quickly that I couldn't because I was really depleting the milk supply every time I gave her formula. I'd go to breastfeed her and there would be nothing there."

"When I breastfed for 3 months, I saved all my cans of milk. I had my whole cupboard full with Enfamil. Full of it. But I still breastfed. I had like 90 cans in the cabinet."

"Then I had to go back to work and my work didn't . . . the type of work that I do, food service, they don't provide a place where you can pump, and you know, store it."

"I just went throughout the day and that's when I got sick. As a matter of fact I was out of work for a couple of days."

"The pumping I think was the hardest part of the whole thing; to try and make sure there was milk here when I'm not."

"I actually breastfed my son when he was crying out of control, and I actually breastfed him on the busand you do not know how many people will stare at you and call you so many obscene names." that WIC designed for them. Second, mothers understand little about the importance of exclusive breastfeeding for good child health outcomes, thereby making formula an innocuous extra for breastfeeding dyads. Third, both WIC and health professionals send contradictory messages about the importance of any or exclusive breastfeeding. Though previously described, ${ }^{20,22,23}$ we would also include an important fourth explanation: There is little social support for lowincome breastfeeding women, including at work and school and in public places, which makes exclusive breastfeeding extremely difficult.

Prior literature has described overall barriers to breastfeeding for low-income women and found that the most common barriers in this population are physical problems with lactation, little confidence in the ability to breastfeed, and "life factors"—such as work, school, caring for other children, and embarrassment at public breastfeeding-that make breastfeeding difficult. ${ }^{20,22,23}$ Prior studies about breastfeeding and WIC have shown peer counseling and professional lactation support to be beneficial, while some standard educational interventions are not. ${ }^{16,17,28}$ Only one study has examined WIC participants and barriers to exclusive breastfeeding, but did not specifically investigate reasons and attitudes about supplementation,or utilization of the expanded food package. ${ }^{19}$ Our study shows that WIC enrollees clearly see the contradiction of WIC as both breastfeeding supporter and formula provider and do not have a basic understanding about the risks of formula supplementation.

The Institute of Medicine has proposed, and the WIC program has accepted, changes to WIC food packages. ${ }^{29}$ One change is that breastfed babies will not receive any formula during the first month postpartum, to help breastfeeding get 
off to the best possible start. In addition, after the first month, partially breastfed infants will receive less formula than fully formula fed infants, to maximize the amount of breastfeeding. Third, mothers' food packages are being enhanced to include both healthier and more culturally acceptable foods, including fresh fruits and vegetables. ${ }^{30}$ This study supports these changes, as they will somewhat diminish the central contradiction of WIC regarding breastfeeding and move the program into a stronger breastfeeding support role.

Our study has several limitations. The findings are from a small sample of WIC-enrolled breastfeeding women from one county in New York State; therefore, results may not be applicable in other regions. Also, women who chose to participate may not be representative of the overall breastfeeding WIC population. Some data are retrospective, and this portion of information is subject to recall bias.

\section{Conclusions}

Incentives to add formula for breastfeeding dyads can be inherent in the WIC program unless specific interventions to support the importance of exclusive breastfeeding and practical advice about how to exclusively breastfeed while working or in public are included for WIC-enrolled mothers. Breastfeeding mothers enrolled in WIC should be offered the expanded food package in lieu of formula and, if they ask for formula supplements, should be informed about how formula can be detrimental to breastfeeding. When upcoming food package changes are made, great consideration should be given to making the expanded food package for exclusively breastfeeding mothers more palatable, acceptable, and useful.

\section{Acknowledgments}

This work was supported by a training grant from the Bureau of Health Professions and a project grant from the Community and Pediatricians Partners for Children Grants Program at the University of Rochester School of Medicine and Dentistry (both to A.V.H.). We are indebted to our partners at our five WIC programs, including Karen Carrier, CLC, Diane Manzler, R.D., and Jim Goetz, M.D. at the Oak Orchard Community Health Center in Brockport, NY; Mary Ann French, M.S., CDN, CLC, Beth O'Sullivan, R.D., Amy Blodgett, R.D., and Andy Doniger, M.D., MPH at the Monroe County Department of Health; and Sasha Paduano, R.D. and Erin Taylor, CLC at the Anthony Jordan Community Health Center in Rochester, NY. Administrative support was provided by Debbie Contestible, Angela Kalish, and Michelle O'Brien at the American Academy of Pediatrics Center for Child Health Research. Finally, we thank the 29 breastfeeding mothers who participated in the interviews, who made this project possible.

\section{Disclosure Statement}

No competing financial interests exist.

\section{References}

1. American Academy of Pediatrics, Section on Breastfeeding. Breastfeeding and the use of human milk. Pediatrics 2005;115:496-506.

2. World Health Organization. Infant and Young Child Nutrition. World Health Organization, Geneva, 2002.
3. American Academy of Family Physicians. AAFP Reference Manual: Selected Policies on Health Issues. American Academy of Family Physicians, Kansas City, MO, 1999.

4. ACOG Educational Bulletin 258: Breastfeeding: Maternal and Infant Aspects. American College of Obstetricians and Gynecologists, Washington, DC, 2000.

5. Ross Products Division, Abbott Laboratories. The Ross Mothers' Survey. Breastfeeding Trends, 2004. Abbott Laboratories, Abbott Park, IL, 2004.

6. Ryan AS, Zhou W. Lower breastfeeding rates persist among the Special Supplemental Nutrition Program for Women, Infants, and Children participants, 1978-2003. Pediatrics 2006;117:1136-1146.

7. Li R, Darling N, Maurice E, et al. Breastfeeding rates in the United States by characteristics of the child, mother, or family: The 2002 National Immunization Survey. Pediatrics 2005;115:e31-e37.

8. Ahluwalia IB, Morrow B, Hsia J, et al. Who is breast-feeding? Recent trends from the pregnancy risk assessment and monitoring system. J Pediatr 2003;143;486-491.

9. Li R, Grummer-Strawn L. Racial and ethnic disparities in breastfeeding among United States infants: Third National Health and Nutrition Examination Survey, 1988-1994. Birth 2002;29:251-257.

10. Centers for Disease Control and Prevention (CDC). Racial and socioeconomic disparities in breastfeeding-United States, 2004. MMWR Morbid Mortal Wkly Rep 2006;55: 335-339.

11. Singh GK, Kogen MD. Persistent socioeconomic disparities in infant, neonatal, and postneonatal mortality rates in the United States, 1969-2001. Pediatrics 2007;119:e928-e939.

12. Ip S, Chung M, Raman G, et al. Breastfeeding and Maternal and Infant Health Outcomes in Developed Countries. Evidence Assessment/Technology Report Number 153. Contract Number 290-02-0022. Agency for Healthcare Research and Quality, Washington, DC, 2007. http://www.ahrq.gov/ downloads/pub/evidence/pdf/brfout/brfout.pdf.

13. Bachrach VR, Schwarz E, Bachrach LR. Breastfeeding and the risk of hospitalization for respiratory disease in infancy: A meta-analysis. Arch Pediatr Adolesc Med 2003;157:237-243.

14. American Academy of Pediatrics, Committee on Nutrition. Prevention of pediatric overweight and obesity. Pediatrics 2003;112:424-430.

15. Food and Nutrition Services, U.S. Department of Agriculture. Legislative History of Breastfeeding Promotion Requirements in WIC. U.S. Department of Agriculture, Washington, DC, updated March 9, 2005. http://www.fns.usda.gov/ wic/Breastfeeding/bflegishistory.htm (accessed October 3, 2007).

16. Anderson AK, Damio G, Young S, et al. A randomized trial assessing the efficacy of peer counseling on exclusive breastfeeding in a predominantly Latina low-income community. Arch Pediatr Adolesc Med 2005;159:836-841.

17. Arlotti JP, Cottrell BH, Lee SH, et al. Breastfeeding among low-income women with and without peer support. J Community Health Nurs 1998;15:163-178.

18. Cricco-Lizza R. The milk of human kindness: Environmental and human interactions in a WIC clinic that influence infant-feeding decisions of black women. Qual Health Res 2005;15:525-538.

19. Finch C, Daniel EL. Breastfeeding education program with incentives increases exclusive breastfeeding among urban WIC participants. J Am Diet Assoc 2002;102:981-983.

20. Feinstein JM, Berkelhamer JE, Gruszka M, et al. Factors related to early termination of breastfeeding in an urban popluation. Pediatrics 1986;73:210-215. 
21. Grossman L, Harter C, Sachs L, et al. The effect of postpartum lactation counseling on the duration of breastfeeding in low-income women. Am J Dis Child 1990;144:471-474.

22. Loughlin $\mathrm{HH}, \mathrm{Clapp}-C h a n n i n g ~ \mathrm{NE}$, Gehlbach $\mathrm{SH}$, et al. Early termination of breastfeeding: Identifying those at risk. Pediatrics 1985;42:504-510.

23. Ertem IO, Votto N, Leventhal JM. The timing and predictors of early termination of breastfeeding. Pediatrics 2001;107:543-548.

24. Hill PD. Predictors of breastfeeding duration among WIC and non-WIC mothers. Public Health Nurs 1991;8:46-52.

25. Raisler J. Against the odds: Breastfeeding experiences of low-income mothers. J Midwifery 2000;45:253-263.

26. Sofaer S. Qualitative methods: What are they and why use them? Health Serv Res 1999;34:1101-1118.

27. U.S. Census Bureau. http://www.census.gov (accessed October 3, 2007).

28. Gross S, Caufield LE, Bentley ME, et al. Counseling and motivational videotapes increase duration of breast-feeding in African-American participants who initiate breast-feeding. $J$ Am Diet Assoc 1998;98:143-148.
29. Institute of Medicine. WIC Food Packages: Time for a Change. Institute of Medicine, Washington, DC, 2005. http://books. nap.edu/openbook.php?record_id $=11280 \&$ page $=1$.

30. U.S. Department of Agriculture, Food and Nutrition Service. Revisions in the WIC Food Packages: Proposed Rule. Federal Register 7 CFR (246), August 27, 2006. http://www.fns. usda.gov/wic/regspublished/foodpackagesrevisionsproposedrulepdf.pdf.

Address reprint requests to: Alison Volpe Holmes, M.D., MPH

Family Health Center Concord Hospital Yeaple Building 250 Pleasant Street Concord, NH 03301

E-mail: aholmes@crhc.org 